RESEARCH REPORT

\title{
Poorer self assessed health in a prospective study of men with screen detected abdominal aortic aneurysm: a predictor or a consequence of screening outcome?
}

\author{
Theresa M Marteau, Lois G Kim, Jane Upton, Simon G Thompson, Alan P Scott ${ }^{*}$
}

J Epidemiol Community Health 2004;58:1042-1046. doi: 10.1136/jech.2003.019307

See end of article for authors' affiliations

Correspondence to: Professor T M Marteau Health Psychology Section (Guy's), 5th Floor Thomas Guy House, London Bridge, London SEl 9RT UK; theresa.marteau@kcl. ac.uk

\begin{abstract}
Study objectives: To assess the extent to which poorer self assessed health in men in whom an abdominal aortic aneurysm (AAA) is detected at screening is a consequence or a predictor of screening outcome. Design: Prospective study.

Setting: Community based screening.

Participants: 23654 men who attended for AAA screening as part of the UK multicentre aneurysm screening study completed a measure of self assessed health before screening. A total of 1156 had an aneurysm detected. A sub-sample of screened men (571 with an aneurysm and 609 with a normal aorta) also completed the measure of self assessed health six weeks after screening.

Main results: Men in whom an aneurysm was detected at screening perceived their health to be poorer before screening than those with a normal aorta. Adjusting for risk factors for AAA made no difference to this result: self assessed health remained a strong predictor of having an aneurysm lodds ratio 1.7 comparing the extreme quartiles of self assessed health, 95\% confidence intervals: 1.4 to 2.0). Men with an aneurysm also perceived their health to be poorer after screening had detected their aneurysms, but only to an extent in line with their pre-screening perceptions.

Conclusions: Self assessed health seems to predict having an aortic aneurysm, independently of known risk factors. This emphasises the importance of assessing baseline perceptions of health to prevent erroneously inferring that poorer self assessed health in those who screen positive is a consequence as compared with a predictor of screening outcome.
\end{abstract}

$\mathrm{S}$ elf assessed health is commonly used to assess the impact of informing participants in screening programmes that they have an increased risk of a health problem. ${ }^{1}$ Poorer self assessed health in those found to be at increased risk is attributed to learning of an increased susceptibility to disease. ${ }^{2-4}$ However, failure to include baseline measures may result in a misattribution given that self assessed health is a strong predictor of health states (particularly mortality) even when controlling for known risk factors. ${ }^{5}$ In most studies the relative risk of mortality for those assessing their health as poor compared with excellent ranges from 1.5 to 3 .

In the multicentre aneurysm screening study (MASS) we found that men in whom an abdominal aortic aneurysm (AAA) was detected rated their health more poorly after receiving their results than did those with a normal aorta. ${ }^{6}$ While these differences may reflect responses to learning of a previously undetected aneurysm, given the strong association between self assessed health and health outcomes, it is possible that such differences may have predated screening. The aim of this study was to use prospective data collected in the MASS trial to assess the extent to which this observed poorer self assessed health after detection of AAA may pre-date the detection of an aneurysm, and the possible explanations for this.

\section{METHODS}

Approval to conduct this study was granted by the Multicentered Research Ethics Committee and the relevant local research ethics committees. In the MASS trial, out of a population based sample of 67800 men aged 65 to 74 years from four centres in the UK, 33839 were randomised to receive an invitation for ultrasound screening. Men with a known AAA, or previous surgery for AAA, were excluded before randomisation. Men randomised to be invited for screening were sent an invitation from their primary care physician, an information booklet, and a questionnaire. On arrival at the clinic to be screened, the screening procedure was explained, the questionnaire was checked, and written consent was taken to participate in the trial.

Altogether 27147 (80\%) men were screened. Men attending screening completed baseline questionnaires and had their blood pressure measured. Complete data were available on self assessed health and the other baseline variables for 23654 of these men (87\% of attendees), of whom 1156 (5\%) then had an aneurysm detected (that is, they had an aortic diameter of three centimetres or greater). Sub-samples of these men (571 with an aneurysm, and 609 with a normal aorta) also completed the measure of self assessed health six weeks after screening. Sampling was conducted by identifying consecutive men in whom aneurysms were detected and selecting the next man down in the list who received a normal screen result. The response rate in both groups was $90 \%$. These sub-samples were comparable to the whole sample of men in terms of age (table 1) and blood pressure, but were from slightly less deprived geographical areas especially in the AAA detected group. The latter may explain the slightly higher self assessed health observed in the subsample than in the whole sample before screening (table 1). Further details of the non-invasive ultrasound screening process and sampling methods are provided elsewhere. ${ }^{6}$

Abbreviations: MASS, multicentre aneurysm screening study; AAA, abdominal aortic aneurysm; BP, blood pressure

*On behalf of the Multicentre Aneurysm Screening Study Group. 
Table 1 Mean (SD) self assessed health in the whole sample and in a sub-sample, according to the detection of an abdominal aortic aneurysm (AAA) at screening

\begin{tabular}{llll}
\hline & AAA detected & No AAA detected & \\
\hline Whole sample & $\mathrm{n}=1156$ & $\mathrm{n}=22498$ & \\
mean age $=69.8$ & mean age $=69.1$ & $\mathrm{p}<0.0001$ \\
Before screening & $64.9(21.3)$ & $69.1(20.3)$ & \\
Sub-sample & $\mathrm{n}=571$ & $\mathrm{n}=609$ & \\
& mean age $=70.0$ & mean age $=69.1$ & $\mathrm{p}=0.009$ \\
Before screening & $66.0(22.1)$ & $69.2(19.8)$ & $\mathrm{p}=0.0004$ \\
After screening & $64.6(22.2)$ & $69.1(20.3)$ & $\mathrm{p}=0.10$ \\
Change & $-1.3(13.8)$ & $-0.1(11.8)$ & \\
\hline
\end{tabular}

\section{MEASURES}

\section{Self assessed health}

This was assessed using responses to five items from the SF36 health survey. ${ }^{7}$ These comprise a single item rating of health (Would you say your health is: excellent, very good, good, fair, poor) and four further items: I seem to get sick a little easier than other people; I am as healthy as anybody I know; I expect my health to get worse; My health is excellent. Scores were transformed to provide a scale range from 0 to 100, with higher scores denoting a higher self assessed health. Men with two or more items missing were excluded from analysis.

\section{Social deprivation}

This was derived from postcodes using the 1991 census. ${ }^{8} 9$ A ward level index of social deprivation was obtained for each participant according to postcode. It is a measurement of overall deprivation, comprising information from six domains: income, employment, education and skills, health and disability, housing, and access to vital services. For the purposes of analysis, the scores were ranked within 8414 wards in England.

\section{Family history}

This was assessed from responses to a question asking whether or not people had any blood relatives who had had a diagnosis of AAA. For the purposes of analysis, those responding yes were compared with those responding no or don't know.

\section{Blood pressure}

The systolic and diastolic blood pressure (BP) measurements used in the analyses are the median of three measurements taken before screening.

\section{Analysis}

Self assessed health in men who had a screen detected aneurysm was compared with that in men with normal aorta using $t$ tests (table 1 ). Multivariate logistic regression was used to ascertain the extent to which this difference might be mediated by known risk factors for AAA (tables 2 and 4). Multivariate normal errors regression was used to investigate the association of these risk factors with self assessed health (rable 3). Continuous variables were analysed as such, but the results in the tables are presented in quartiles for ease of interpretation.

\section{RESULTS}

Self assessed health before screening was poorer for men in whom an AAA was detected compared with those in whom a normal aorta was recorded (table 1). A similar difference was evident both before and after screening in the sub-sample in whom self assessed health was measured at these two time points. After screening, although the observed mean decline in self assessed health was greater in men with an aneurysm

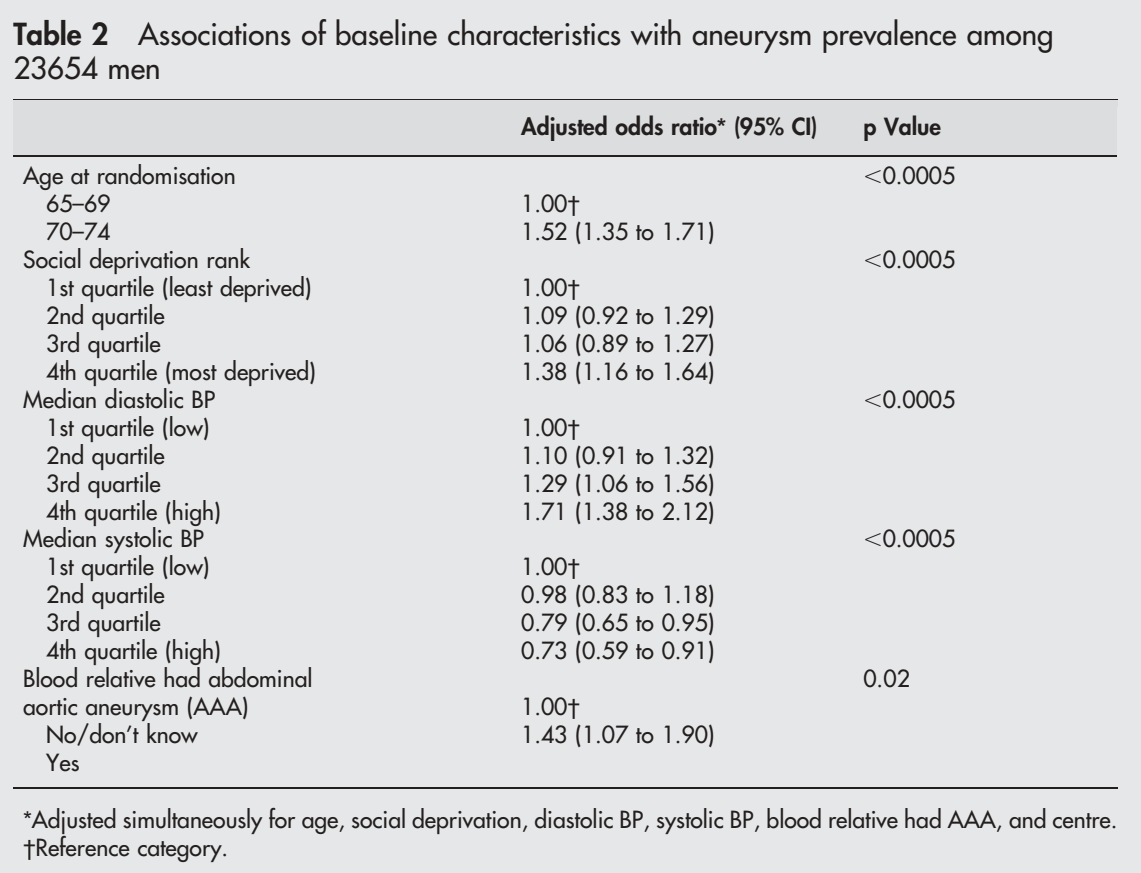


Table 3 Associations of baseline characteristics with self assessed health in 23654 men

\begin{tabular}{|c|c|c|}
\hline & $\begin{array}{l}\text { Adjusted mean differences in self } \\
\text { assessed health* }(95 \% \mathrm{CI})\end{array}$ & $p$ Value \\
\hline $\begin{array}{l}\text { Age at randomisation } \\
65-69 \\
70-74\end{array}$ & $\begin{array}{l}0.00 \dagger \\
-1.5(-2.1 \text { to }-1.0)\end{array}$ & $<0.0005$ \\
\hline $\begin{array}{l}\text { Social deprivation rank } \\
\text { 1st quartile (least deprived) } \\
\text { 2nd quartile } \\
\text { 3rd quartile } \\
\text { 4th quartile (most deprived) }\end{array}$ & $\begin{array}{l}0.00 \dagger \\
-0.3(-1.0 \text { to } 0.4) \\
-1.7(-2.5 \text { to }-1.0) \\
-3.8(-4.6 \text { to }-3.0)\end{array}$ & $<0.0005$ \\
\hline $\begin{array}{l}\text { Median diastolic BP } \\
\text { 1st quartile (low) } \\
\text { 2nd quartile } \\
\text { 3rd quartile } \\
\text { 4th quartile (high) }\end{array}$ & $\begin{array}{l}0.00 \dagger \\
1.8(1.0 \text { to } 2.6) \\
2.5(1.7 \text { to } 3.4) \\
1.9(1.0 \text { to } 2.9)\end{array}$ & $<0.0005$ \\
\hline $\begin{array}{l}\text { Median systolic BP } \\
\text { 1st quartile (low) } \\
\text { 2nd quartile } \\
\text { 3rd quartile } \\
\text { 4th quartile (high) }\end{array}$ & $\begin{array}{l}0.00 \dagger \\
1.6(0.8 \text { to } 2.3) \\
0.3(-0.5 \text { to } 1.1) \\
-0.2(-1.2 \text { to } 0.7)\end{array}$ & 0.96 \\
\hline $\begin{array}{l}\text { Blood relative had abdominal } \\
\text { aortic aneurysm (AAA) } \\
\text { No/don't know } \\
\text { Yes }\end{array}$ & $\begin{array}{l}0.00 \dagger \\
-3.2(-4.7 \text { to }-1.8)\end{array}$ & $<0.0005$ \\
\hline
\end{tabular}

detected than in those without, the difference was not statistically significant (table 1).

Age, social deprivation, diastolic blood pressure, and family history were all predictors both of having an aneurysm and level of self assessed health (tables 2 and 3). Systolic blood pressure was an additional predictor of having an aneurysm, but not of self assessed health.

Even after adjustment for all other factors, self assessed health remained as strong a predictor of having an aneurysm: the lower a man's perceived health before screening,

Table 4 Associations of baseline characteristics, including self assessed health, with aneurysm prevalence among 23654 men

\begin{tabular}{|c|c|c|}
\hline $\begin{array}{l}\text { (A) Univariate-self assessed } \\
\text { health only }\end{array}$ & Odds ratio $(95 \% \mathrm{Cl})$ & $\mathrm{p}$ Value \\
\hline Self assessed health & & $<0.0005$ \\
\hline 1 st quartile (best) & $1.00+$ & \\
\hline 2nd quartile & $1.25(1.05$ to 1.49$)$ & \\
\hline 3rd quartile & $1.32(1.12$ to 1.57$)$ & \\
\hline 4th quartile (worst) & $1.71(1.46$ to 2.01$)$ & \\
\hline (B) Multivariate - all baseline & & \\
\hline variables & Adjusted odds ratio* $(95 \% \mathrm{Cl})$ & p Value \\
\hline Age at randomisation & & $<0.0005$ \\
\hline $65-69$ & $1.00 \dagger$ & \\
\hline $70-74$ & $1.50(1.33$ to 1.69$)$ & \\
\hline Social deprivation rank & & 0.001 \\
\hline 1st quartile (least deprived) & $1.00+$ & \\
\hline 2nd quartile & $1.09(0.92$ to 1.29$)$ & \\
\hline $3^{\text {rd }}$ quartile & $1.05(0.88$ to 1.25$)$ & \\
\hline 4th quartile (most deprived) & $1.33(1.12$ to 1.59$)$ & \\
\hline Median diastolic BP & & $<0.0005$ \\
\hline 1st quartile (low) & $1.00+$ & \\
\hline 2nd quartile & $1.12(0.93$ to 1.35$)$ & \\
\hline 3rd quartile & $1.32(1.09$ to 1.60$)$ & \\
\hline 4th quartile (high) & $1.74(1.41$ to 2.16$)$ & \\
\hline Median systolic BP & & $<0.0005$ \\
\hline 1st quartile (low) & $1.00+$ & \\
\hline 2nd quartile & $1.00(0.84$ to 1.20$)$ & \\
\hline 3rd quartile & $0.79(0.65$ to 0.96$)$ & \\
\hline 4th quartile (high) & $0.73(0.59$ to 0.91$)$ & \\
\hline Blood relative had abdominal & & 0.03 \\
\hline aortic aneurysm (AAA) & $1.00+$ & \\
\hline $\begin{array}{l}\text { No/don't know } \\
\text { Yes }\end{array}$ & $1.38(1.04$ to 1.84$)$ & \\
\hline $\begin{array}{l}\text { Tes } \\
\text { Self assessed health }\end{array}$ & & $<0.0005$ \\
\hline 1 st quartile (best) & $1.00+$ & \\
\hline 2nd quartile & $1.24(1.05$ to 1.48$)$ & \\
\hline 3rd quartile & $1.32(1.11$ to 1.56$)$ & \\
\hline 4th quartile (worst) & $1.66(1.41$ to 1.95$)$ & \\
\hline
\end{tabular}




\section{Key points}

- Self assessed health is often used as an outcome of screening

- We found that self assessed health predicted having an aortic aneurysm independently of known risk factors

- Self assessed health needs to be measured before screening to prevent erroneously inferring that poorer self assessed health in those who screen positive is a consequence as compared with a predictor of screening outcome

the greater the chances that an aneurysm was detected (table 4).

\section{DISCUSSION}

Self assessed health predicts having an aortic aneurysm, independently of known risk factors. Thus, the difference observed in self assessed health after screening, between those found to have an aneurysm and those not, principally reflects the pre-existing difference. Although there may be some additional decline in self assessed health in men who screen positive, the difference observed after screening does not, in large part, reflect an adverse effect on self assessed health of learning of an aneurysm, with its attendant risk of premature death. To our knowledge this is the first study to report self assessed health as an independent predictor of AAA.

There are several possible explanations for these findings. Self assessed health may predict AAA because it reflects a judgement based on the risk factors for this condition. The main known risk factors are family history, age, blood pressure, and smoking. ${ }^{10}{ }^{11}$ There was partial evidence to support this explanation here in that self assessed health was predicted by the first three of these risk factors. Although smoking was not assessed at baseline in this study, other studies have shown that smokers perceive their health more poorly than non-smokers. ${ }^{12}{ }^{13}$ It is therefore possible that if smoking had been measured at baseline, self assessed health would not have made an independent contribution to explaining the risk of AAA. Two sets of evidence suggest that this is unlikely. Firstly, analysis of smoking information collected in our study on those in whom an aneurysm was detected did not provide convincing evidence that smoking status was related to self assessed health. Secondly, it has been observed that the odds of mortality for those with poor self assessed health often exceed the odds of mortality for smokers when they are reported in the same study. ${ }^{5}$

Another possible explanation for the observation that self assessed health is an independent predictor of having an aneurysm is that individual's judgements of their health go

\section{Policy implications}

Self assessed health is sometimes used as an index of quality of life. Given self assessed health is an independent predictor of mortality, healthcare interventions that impair self assessed health raise concerns. Our observation that poorer self assessed health predates the detection of an aortic aneurysm in screening heralds caution in inferring that self assessed health is a consequence of a particular intervention, in this case the detection of an aneurysm, as compared with a correlate of it. beyond known risk factors to encompass other variables that both reflect and reinforce health status. Stenback ${ }^{14}$ suggested that the patient, in contrast with the clinician, has access to sensations that predict health outcomes but that are inaccessible to others. While those with very large aneurysms do sometimes report symptoms, no such reports were recorded at initial screening in the MASS, even though detected aneurysms ranged in size from $3 \mathrm{~cm}$ to $13 \mathrm{~cm}$. Self assessed health may reflect personal resources, psychological, social, and material, that can accelerate or attenuate a decline in health. It therefore remains an open question as to whether self assessed health is an independent predictor of aneurysm prevalence because it is a more complete summary of salient risk factors than those assessed in this study or because it encompasses a broader range of factors that predict having an aneurysm.

Explaining the predictive power of self assessed health has eluded satisfactory explanation to date. There is good evidence to show that its predictive power is stronger in men than women, ${ }^{15-18}$ an effect most probably attributable to the different sets of information men and women draw upon in rating their health. Men's judgements more closely reflect serious life threatening illnesses, whereas women's judgements reflect both life threatening and non-life threatening conditions, such as joint disease. ${ }^{19}$ None the less, Idler and Benyamini $^{5}$ observed that a very long list of variables is necessary to explain this phenomenon. They also note that, given the power of self assessed health to predict health outcomes is now established, the next generation of research studies need to test hypotheses to explain this.

In conclusion, the results of this study have implications both for the methods used to assess the psychological impact of AAA screening, and for understanding the causes of AAA. Recognising that self assessed health is a predictor of actual health status, in this case having an aneurysm detected at screening, highlights the importance of measuring self assessed health before measuring health status. Failure to do so can lead to the erroneous conclusion that detection of an adverse health status results in poorer self assessed health as a consequence of its detection. The results from this study suggest that poorer self assessed health in men with an AAA pre-dates its detection, an association that is not explained by the relations between self assessed health and known risk factors for aneurysms. Understanding this association may shed some light on hitherto unrecognised risk factors that might lead to new ways of preventing AAA. We are unaware of other studies that have examined self assessed health as a predictor of outcomes in other screening programmes. The results of this study suggest this merits investigation.

\section{Authors' affiliations}

T M Marteau, Health Psychology Section (Guy's), Department of Psychology, Institute of Psychology, King's College London, UK L G Kim, S G Thompson, MRC Biostatistics Unit, Cambridge, UK J Upton, Research Centre for Health Studies, Buckinghamshire Chilterns University College, UK

A P Scott, St Richards Hospital, Chichester, West Sussex, UK

Funding: the MASS trial was funded by the Medical Research Council (GP533930).

Conflicts of interest: none declared.

\section{REFERENCES}

1 Shaw C, Abrams K, Marteau TM. Psychological impact of predicting individuals' risk of illness: a systematic review. Soc Sci Med 1999;49:1571-98.

2 Bloom JR, Monterossa S. Hypertension labeling and sense of well-being. Am J Public Health 1981;71:1228-32.

3 Havas S, Reisman J, Hsu L, et al. Does cholesterol screening result in negative labeling effects? Arch Intern Med 1991;151:113-19. 
4 Houts PS, McDougall V. Effects of informing workers of their health risks from exposure to toxic materials. Am J Ind Med 1988;13:271-9.

5 Idler EL, Benyamini Y. Self-rated health and mortality: a review of twentyseven community studies. J Health Soc Behav 1997;38:21-37.

6 The Multicentre Aneurysm Study Group. The multicentre aneurysm screening study (MASS) into the effect of abdominal aortic aneurysm screening on mortality in men: a randomised controlled trial. Lancet 2002;360:1531-9.

7 Ware J, Gandeck B. Overview of the SF-36 health survey and the international quality of life assessment (IQOLA) project. $J$ Clin Epidemiol 1998:51:903-12.

8 Noble M, Penhale B, Smith G, et al. Indices of deprivation: regeneration research summary. Vol 31. London: Department of the Environment, Transport and the Regions, 2000.

9 Simpson L, Yu A, Avenell D, et al. All fields postcode directory (AFPD). Updated UK masterfiles (2001). (http://convert.mimas.ac.uk).

10 Lederle FA, Johnson GR, Wilson SE, et al. The aneurysm detection and management study screening programme. Validation cohort and final results. Arch Intern Med 2000;160:1425-30.

11 Vardulaki KA, Walker NM, Day NE, et al. Quantifying the risk of hypertension, age, sex and smoking in patients with abdominal aortic aneurysm. Br J Surg 2000;87:195-200.
12 Meurer LN, Layde PM, Guse CE. Self-rated health status: a new vital sign for primary care? Wis Med J 2001;100:35-9.

13 Vingilis ER, WadeTJ, Seeley JS. Predictors of adolescent self-rated healthanalysis of the National Population Health Survey. Can J Public Health 2002;93:193-7.

14 Stenback A. Physical health and physical disease as objective fact and subjective experience. Arch Gen Psychiatry 1964;11:290-301.

15 Idler EL, Russell LB, Davis D. Survival, functional limitations, and self-rated health in the NHANES-I epidemiologic follow-up study. 1992. First National Health and Nutrition Examination Survey. Am J Epidemiol 2000;152:874-83

16 Idler EL, Kasl SV. Health perceptions and survival: do global evaluations of health status really predict mortality? J Gerontol 1991;46:S55-65.

17 Idler EL, Angel RJ. Self-rated health and mortality in the NHANES-1 epidemiologic follow-up study. Am J Public Health 1990;80:446-52

18 Murray J, Dunn G, Tarnopolsky A. Self-assessment of health: an exploration of the effects of physical and psychological symptoms. Psychol Med 1982;12:371-8.

19 Benyamini Y, Leventhal EA, Leventhal H. Gender differences in processing information for making self-assessments of health. Psychosom Med 2000;62:354-64

\section{$\mathrm{ECHO}$}

\section{Current smoking and the risk of non-fatal myocardial infarction in the WHO MONICA Project populations}

M S Mähönen, P McElduff, A J Dobson, K A Kuulasmaa, A E Evans, for the WHO MONICA Project

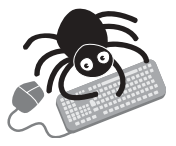

Please visit the Journal of Epidemiology and

Community Health website [www.jech. com] for a link to the full text of this article.
Background: Cohort studies have shown that smoking has a substantial influence on coronary heart disease mortality in young people. Population based data on non-fatal events have been sparse, however.

Objective: To study the impact of smoking on the risk of non-fatal acute myocardial infarction (MI) in young middle age people.

Methods: From 1985 to 1994 all non-fatal MI events in the age group 35-64 were registered in men and women in the WHO MONICA (multinational monitoring of trends and determinants in cardiovascular disease) project populations ( 18762 events in men and 4047 in women from 32 populations from 21 countries). In the same populations and age groups 65741 men and 66717 women participated in the surveys of risk factors (overall response rate $72 \%$ ). The relative risk of non-fatal MI for current smokers was compared with nonsmokers, by sex and five year age group.

Results: The prevalence of smoking in people aged 35-39 years who experienced non-fatal MI events was $81 \%$ in men and $77 \%$ in women. It declined with increasing age to $45 \%$ in men aged 60-64 years and 36\% in women, respectively. In the 35-39 years age group the relative risk of non-fatal MI for smokers was 4.9 (95\% confidence interval (CI) 3.9 to 6.1) in men and 5.3 (95\% CI 3.2 to 8.7 ) in women, and the population attributable fractions were $65 \%$ and $55 \%$, respectively.

Conclusions: During the study period more than half of the non-fatal MIs occurring in young middle age people can be attributed to smoking.

A Tobacco Control 2004;13:244-250 